\title{
Does The Day Of The Week Effect Exist Once Transaction Costs Have Been Accounted For? Evidence From The UK
}

\author{
THIS ARTICLE HAS BEEN PUBLISHED IN: \\ APPLIED FINANCIAL ECONOMICS, 2004, Vol. 14, pp. 215-220
}

\author{
A. GREGORIOU, A. KONTONIKAS and N. TSITSIANIS \\ DEPARTMENT OF ECONOMICS AND FINANCE, BRUNEL UNIVERSITY, UXBRIDGE, \\ MIDDLESEX, UB8 3PH, UK
}

This article investigates the day of the week anomaly in the FTSE 100 Share Index over an 11-year time period from 1 January 1986 to 31 December 1997. Its focus is to assess whether the day of the week effect continues to persist once transactions costs are considered. Unlike previous literature it uses the bid-ask spread as a proxy for transactions costs. It finds that once returns become robust to transactions costs the anomaly appears to fade away. It then extends the research by looking at the time-varying volatility of stock returns with use of a GARCH model. The GARCH results further support the fact that transaction costs appear to die away the day of the week anomaly in the UK Stock market.

\section{INTRODUCTION}

Since the initiatory work of Fama (1965), who was the first to document the anomalies exhibited by security price returns, there has been a vast amount of research in this area. In recent years a vast amount of evidence has been accumulated on the existence of calendar anomalies in stock returns ${ }^{1}$. The most prevalent of these anomalies turns out to be the day of the week effect. Since French (1980) originally observed that stock returns are higher on average on the last trading day of the week (Friday) and lower on the first (Monday), many studies have attempted to explain what has come to be known as the day of the week effect. Convincing evidence has been carried out to support the conclusion that there is a day of the week on stock returns in the USA (see, for example, Linn and Lockwood, 1988), although recent evidence for the US casts doubt on these findings and observes that this effect has died out ${ }^{2}$. Explanations preferred for this phenomenon are inclusive of market settlement procedures (Gibbons and Hess, 1981), measurement errors in stock prices (Keim and Stambaugh, 1984) and the tendency for firms to release adverse information after trading closes for the weekend. Though plausible, each of these hypotheses offers only weak support. Moreover, Connolly (1989) using US data (adjusted for sample size, heteroscedasticity and serial correlation) reported that day of the week effects disappeared in the US equity markets after 1975. With respect to the UK stock market Mills and Coutts (1995) and Arsad and Coutts (1997) have both found evidence that a day of the week effect exists in the UK stock market. Day of the week effects alongside seasonal and holiday patterns (anomalies) ${ }^{3}$ have existed for over half a century and led some financial economists to question the notion of market efficiency, and in particular, the capital asset pricing model

\footnotetext{
${ }^{1}$ Partial surveys may be found in Thaler (1987a, 1987b).

${ }^{2}$ Selective papers include Fama (1965), Cross (1973), French (1980), Lakonishok and Levi (1982), Keim and Stambaugh (1984) and Connolly $(1989,1991)$.

${ }^{3}$ A considerable body of empirical evidence documents the impact of seasonal and holiday patterns on security returns. Although important, the aim of the current article is to focus on the day of the week effect.
} 
(CAPM) and asset pricing theory (APT). Mills and Coutts (1995) pointed out the need for new, alternative, models of asset pricing.

Lakonishok and Smidt (1988) were the first to draw attention to the fact that it might be wise to adopt a sceptical stance against the existence of anomalies until they have been supported by studies utilising datasets coming from different stock markets over different time periods. As Arsad and Coutts (1997) noted, relatively little research has been undertaken on regularities regarding the UK stock exchange data. Furthermore, as Bowers and Dimson (1988) pointed out, international contrasting provides the means for researchers to examine whether the US findings are also persistent, at least to some extent, elsewhere. Such comparisons are of importance because stock market anomalies and their explanations are often attributed to the conditions stemming from individual markets and economies. Therefore, documentation of their existence in the first place and assessment of their tenacity across markets is of interest.

Nevertheless, it is not the purpose of this article to offer new explanatory evidence of security market regularities; instead, its main aim is to document the existence of these irregularities, especially the day of the week effect. There has been some disagreement over the size, timing or solidity of the weekend effect. As noted above, efforts to explain the weekend effect have reached inconclusive results. Furthermore, apart from documenting these effects using an expanded dataset, this article also focuses on two issues.

First, as noted previously, Coutts and his counterparts report a significant weekend effect using UK data. They also note that if transaction costs are taken into consideration the day of the week effect practically disappears. However, they looked at brokerage fees to represent transaction costs. These vary considerably and differ from broker to broker, implying that they do not represent an accurate measure of transaction costs. This article considers the bid-ask spread as its measure of transaction costs. One of the most important characteristics that investors look for in an organized financial market is liquidity. Liquidity is the ability to buy or sell significant quantities of a security quickly, anonymously, and with relatively little price impact. To maintain liquidity, many organized exchanges use market makers, who are individuals that stand ready to buy or sell whenever the public wishes to buy or sell. In return for providing liquidity, market makers are granted monopoly rights by the exchange to post different prices for purchases and sales. They buy at the bid price, $\mathrm{Pb}$ and sell at a higher ask price $\mathrm{Pa}$. This ability to buy low and sell high is the market makers' primary source of compensation for providing liquidity. Their compensation is defined as $\mathrm{Pa}-\mathrm{Pb}$, which is known as the bid-ask spread. This is a much better representation of transactions costs since they are quoted for each stock. So the data is universally available and there is one figure representing transactions costs for each stock.

Second, there is mounting evidence that stock returns exhibit time-varying volatility. As Connolly (1989) argued, Bollerslev's (1987) GARCH model offers several advantages: it incorporates heteroscedasticity in a sensible way (for a time series), it can be expanded to include other relevant variables in the conditional variance equation, and generally it offers more flexibility in robust modelling of stock returns.

The structure of the article is as follows: the next section discusses the data in more detail and sets out the methodology. Section III offers statistical evidence relating to the weekend anomalies coupled with the introduction of transaction costs. Section IV introduces a more robust modelling of stock returns, namely GARCH. The last section examines the implications of the findings and draws some conclusions.

\section{DATA}

The Financial Times Stock Exchanges 100 (FTSE 100) is the major UK share index on the London Stock Exchange, and its computation began on 1 July 1935. The FTSE 100 Index comprises of the 100 largest sized companies (by market value) that are listed in the UK stock market. FTSE 100 is also considered to be a surrogate for the movements taking place in London Stock Exchange and is ideal for investigating stock market anomalies since it includes a capacious industrial base, and the fact that its constituent securities are frequently traded largely diminishes the problem of 'thin trading'. Since one is looking at the day of the week effect one collects daily data. Daily prices of the FTSE 100 Share Index from 1 January 1986 until 31 December 1997 were collected, giving a sample of 3131 observations after holidays have been excluded. Ideally, the years prior to 1 January 1986 could also be included, yet data unavailability of the bid-ask spread prevented us from doing so. Daily prices were converted into daily returns by using continuous compounding ${ }^{4}$.

\footnotetext{
${ }^{4}$ This is the standard formula that is used for computed daily returns from daily stock prices. For more details on this see Arsad and Coutts (1997).
} 
Daily returns are calculated as:

$$
R_{t}=\ln \left(P_{t} / P_{t-1}\right)
$$

where $R_{t}$ denotes the stock return at time period $t$; where Pt denotes the stock price index at time period $t$; where $\mathrm{P}_{\mathrm{t}-1}$ denotes the stock price index at time period $\mathrm{t}-1$. An 11-year sample period was selected because one wants to examine whether the day of the week effect persists over time and in order to do this one requires a relatively long time series. This particular sample period was selected since it covered some interesting economic events such as the deregulation of the London Stock Exchange in October 1986, the market crash of October 1987, and the 1997 Asian financial crisis. This implies that if a day of the week effect exists during a time period of major economic events, then the day of the week effect is a strong anomaly of the stock market that is insistent over time.

Table 1. Sammary statistics, sample: I Vanuary 1986-31 December 1997

\begin{tabular}{lcccccc}
\hline & $R_{1}$ & Monday $R_{1,}$ & Tuesday $R_{2,}$ & Wednesday $R_{3 t}$ & Thursday $R_{4,}$ & Friday $R_{5,}$ \\
\hline Mean & 0.000412 & -0.000167 & 0.000154 & 0.000188 & $7.35 \mathrm{E}-05$ & 0.000164 \\
Median & 0.000319 & 0.000000 & 0.000000 & 0.000000 & 0.000000 & 0.000000 \\
Maximum & 0.075970 & 0.026558 & 0.029759 & 0.075970 & 0.043444 & 0.054396 \\
Minimum & -0.130286 & -0.114774 & -0.130286 & -0.028083 & -0.058582 & -0.029074 \\
SD & 0.009196 & 0.004547 & 0.004359 & 0.003839 & 0.003840 & 0.003933 \\
Skewness & -1.587764 & -7.044140 & -8.647377 & 2.934316 & -0.448349 & 1.478463 \\
Kurtosis & 27.33050 & 135.6432 & 268.4086 & 63.42169 & 40.13583 & 31.63700 \\
Jarque-Bera & $78645.3 * *$ & $3064585^{* * *}$ & $9225784^{* * *}$ & $480614.3 * * *$ & $179958.5 * *$ & $108092.1^{* * *}$ \\
\hline
\end{tabular}

Notes: *,***** represent levels of significance of 10,5 and $1 \%$ respectively.

$R_{i l}=D_{i l} R_{f}$, for $i=1-5$.

The data does not incorporate information about the payments of dividends. This is because the exclusion of dividends may not be so crucial as it initially seems, since the immense majority of studies documenting anomalies in stock prices have not recorded dividend-adjusted returns. Indeed, Mills and Coutts (1995) using British data claimed that the exclusion of dividends may not negatively affect the findings of the analysis. Lakonishok and Smidt (1988) using Dow Jones Industrial Index data over a period of 90 years reported that the results remained virtually unchanged regardless of the dividend adjustment in their examination of irregularities. Fishe et al. (1993) confirmed these findings using S\&P 500 and CSPR indices. They claimed that any bias stemming from not employing dividend-adjusted returns is relatively small and it is not powerful enough to eliminate the Monday effect or to render any impact insignificant.

On the other hand, seasonalities in dividends payoffs might induce seasonal patterns in non-dividend adjusted returns. It is in this spirit that Philips-Patrick and Schneeweis (1988) for example, utilizing S\&P 500 index, pointed out the significant influence exerted by dividend yields after they have been included in the estimation of daily returns for the observed weekend effect. As a consequence, one needs to take account of this potential shortcoming before attempting to make any conclusions.

\section{The Day of the Week Effect}

Table 1 contains summary statistics for the daily FTSE 100 index returns, and also for the returns of each individual working day of the week. As expected, stock returns are leptokurtic and non-normal ${ }^{5}$. Table 1 indicates that Monday returns, as opposed to the other days' returns, exhibit the lowest mean and highest standard deviation. The greater variance could be attributable to the higher trading volume instigated by the existence of the anomaly.

The conventional methodology employed in the anomalies' literature was utilized in order to test for a day of the week effect (see Arsad and Coutts, 1997). Thus, daily returns are regressed on five dummy variables each one representing a day of the working week to see whether there is any statistically significant difference among returns on different days: The methodology used is shown in Equation 1.

$$
R t=\beta_{1} D_{1 t}+\beta_{2} D_{2 t}+\beta_{3} D_{3 t}+\beta_{4} D_{4 t}+\beta_{5} D_{5 t}+\varepsilon_{t}
$$

where $R_{t}$, and $D_{1 t-} D_{5 t}$ denote the returns on the FTSE 100 share index, and five dummy variables, respectively. $D_{1 t}$ takes the value 1 if day $t$ is a Monday, and 0 otherwise, $D_{2}$ takes the value 1 if day $t$ is

\footnotetext{
${ }^{5}$ See Fama (1965), Badrinath and Chatterjee (1991), Aggarwal et al. (1989) for further details.
} 
Tuesday, and zero otherwise, and so on. The equation is estimated with the use of a standard OLS regression. The coefficients $\beta_{1}-\beta_{5}$ denote the mean returns for Monday to Friday respectively. The error term is indicated by $\varepsilon$ t. One assumes that the error term follows a normal distribution with a mean of zero and a variance of $\sigma^{2}$. The null hypothesis under investigation is:

$$
H_{0}=\beta_{1}=\beta_{2}=\beta_{3}=\beta_{4}=\beta_{5 t}(=0)
$$

against the alternative that all $\beta$ s are not equal. If the null hypothesis is rejected then the stock returns must exhibit some form of the day-of-the-week seasonally, since the returns differ from each trading day.

\section{STATISTICAL EVIDENCE REGARDING THE DAY OF THE WEEK EFFECT IN THE FTSE INDICES}

This section reports evidence concerning the existence of the day of the week effect discussed above in the FTSE indices. In line with previous evidence, the results reported by Table 2 (second row) indicate the rejection by the F-statistic of the null of no day of the week effects. The mean return on Monday is significantly negative, while the returns for the other days are generally positive. In order to take into account the influence of transactions costs, Equation 1 was re-estimated employing spread-adjusted returns as the dependent variable. Spread-adjusted returns (RS) were calculated using the following formula:

$$
\mathrm{RS}_{\mathrm{t}}=\Delta \ln \left(\mathrm{P}_{\mathrm{t}}-\mathrm{St}_{\mathrm{t}}\right)
$$

where $\mathrm{P}_{\mathrm{t}}$ denotes the stock price index at time period $\mathrm{t}$; where $\mathrm{St}$ denotes the bid-ask spread at time period $\mathrm{t}$; where $\Delta$ denotes the first difference operator. Once transactions costs are accounted for Equation 1 becomes Equation 2 which is the following:

$$
R S_{t}=\beta_{1} D_{1 t}+\beta_{2} D_{2 t}+\beta_{3} D_{3 t}+\beta_{4} D_{4 t}+\beta_{5} D_{5 t}+\varepsilon t
$$

The striking result in Table 2 (third row) is that, once transactions costs have been accounted for, there appears to be no significantly (negative) Monday effect. The $\beta$ coefficient on the Monday-dummy is still negative, but insignificant at the convenient levels of significance.

Table 2. Estimates of models 1 and 2 or the period 2 Jamuary 1986-31 December 1997

\begin{tabular}{lll}
\hline Coefficient & Model 1 & Model 2 \\
\hline$\beta_{1}$ & $-0.00084^{* *}$ & -0.00049 \\
(Monday) & $(-2.0636)$ & $(-0.8934)$ \\
$\beta_{2}$ & $0.00077^{* *}$ & 0.00057 \\
(Tuesday) & $(1.977)$ & $(1.0719)$ \\
$\beta_{3}$ & $0.00094^{* * *}$ & $0.00129^{* * *}$ \\
(Wednesday) & $(2.7524)$ & $(2.4791)$ \\
$\beta_{4}$ & 0.000368 & -0.00012 \\
(Thursday) & $(1.0713)$ & $(-0.2565)$ \\
$\beta_{5}$ & $0.000822^{* * *}$ & $0.00081^{*}$ \\
(Friday) & $(2.3454)$ & $(1.8011)$ \\
F-statistic & $4.478^{* * *}$ & $2.281^{* * *}$ \\
\hline
\end{tabular}

Notes: The number in parentheses denote robust $t$-statistics. $*$, **, *** represent levels of significance of 10,5 and $1 \%$ respectively. 


\section{GARCH MODEL OF STOCK RETURNS AND THE ROLE OF TRANSACTION COSTS}

In order to gain more insight into the Monday effect, one decided to look at the variance of the returns on Mondays more closely. One followed Connolly (1989) by employing a GARCH specification for the conditional variance of daily stock returns. As Connolly argued, Bollerslev's (1987) GARCH model offers several advantages: it incorporates heteroscedasticity in a sensible way (for a time series), it can be expanded to include other relevant variables in the conditional variance equation, and generally it offers more flexibility in robust modelling of stock returns.

Table 3 reports tests for time-varying volatility in the residuals of models 1 and 2 . The test involves regressing the squared OLS residuals from the conditional mean equation $\varepsilon^{2}$ tagainst a constant and their lagged values:

$$
\varepsilon^{2}{ }_{t}=\alpha_{0}+\alpha_{1} \varepsilon_{t-1}^{2}+\alpha_{2} \varepsilon_{t-2}^{2}+\ldots+\alpha_{q} \varepsilon_{t-q}^{2}+v_{t}
$$

where the null hypothesis of constant variance (homoscedasticity) implies that:

$$
\alpha_{1}=\alpha_{2}=\ldots=\alpha_{q}=0
$$

\begin{tabular}{|c|c|c|c|c|c|c|}
\hline \multirow[b]{2}{*}{$q$} & \multicolumn{2}{|l|}{ F-statistic } & \multicolumn{2}{|l|}{$\mathrm{TR}^{2}$} & \multicolumn{2}{|l|}{$Q^{2}$} \\
\hline & Model I & Model 2 & Model I & Model 2 & Model I & Model 2 \\
\hline 1 & $1719.8^{\circ}$ & $3301.83^{* 00}$ & $1110.27^{* 46}$ & $1532.55^{\circ 64}$ & 1111.7000 & $1534.5^{*+4}$ \\
\hline 4 & $467,08^{* * * *}$ & $780.95^{* * *}$ & $1170.58^{* * *}$ & $1563.72^{* * *}$ & $1478.5^{* * * *}$ & $2267,9^{* * *}$ \\
\hline 8 & $235.98 \cdots$ & $399.06 \div$ & $1178,59^{* * *}$ & $1580.67^{\cdots * *}$ & $15449^{\circ \cdots}$ & $2310.7^{* 0 *}$ \\
\hline 12 & $158.24^{6.44}$ & $271.84^{646}$ & $1183.25^{4+4}$ & $1597,42^{644}$ & $1601.3^{646}$ & $2342.8^{4+4}$ \\
\hline
\end{tabular}

Table 3. Tesing for lime-rarying residual variance in models 1 and 2

Nofes: $", ", \cdots *$ represent levels of significance of 10,5 and $1 \%$ respectively.

The test can implemented with either the use of an F-statistic which tests the joint significance of all lagged squared residuals, or with Engle's LM-statistic computed as the number of observations times the R2. The LM statistic follows a chi-squared distribution asymptotically. Bollerslev (1986) showed that the LM test for a qth order $\mathrm{ARCH}$ is equivalent to a test for $\mathrm{GARCH}(\mathrm{i}, \mathrm{j})$ where $\mathrm{i}+\mathrm{j}=\mathrm{q}$.

There is overwhelming evidence that the residuals of models 1 and 2 exhibit time varying variance. The $F$ and $R^{2}$ test-statistics are significant at the $1 \%$ level at all lags, while the Ljung-Box $Q$-statistics of the squared residuals $\left(Q^{2}\right)$ are all significant at the $1 \%$ level implying that the squared residuals exhibit the classic volatility clustering of an $\mathrm{ARCH}$ process.

\begin{tabular}{|c|c|c|c|c|c|}
\hline \multirow[b]{2}{*}{ Coefficient } & \multicolumn{2}{|c|}{ Conditional mean equation } & \multirow[b]{2}{*}{ Coefficient } & \multicolumn{2}{|c|}{ Conditional variance equation } \\
\hline & Model 5 & Model 6 & & Model 5 & Model 6 \\
\hline $\begin{array}{l}\beta_{1} \\
\text { (Mondav) }\end{array}$ & $\begin{array}{l}-0.000557^{*} \\
(-1.7521)\end{array}$ & $\begin{array}{l}4.74 \mathrm{E}-05 \\
(0.112)\end{array}$ & $\alpha_{0}$ & $\begin{array}{l}2.43 \mathrm{E}-07 \\
(0.084)\end{array}$ & $\begin{array}{l}3.11 \mathrm{E}-06 \\
(0.5537)\end{array}$ \\
\hline$\beta_{2}$ & $0.001056^{* * *}$ & 0.00058 & $\alpha_{1}$ & $0.10478^{* * *}$ & $0.114^{* * * *}$ \\
\hline (Tuesday) & $(3.584)$ & $(1.4791)$ & & (3.994) & $(2.75)$ \\
\hline$\beta_{3}$ & $0.001321^{* * *}$ & $0.00144^{* * *}$ & $\alpha_{2}$ & $0.8429^{* * *}$ & $0.832^{* * * *}$ \\
\hline (Wednesday) & $(3.581)$ & $(2.3632)$ & & $(25.531)$ & (19.506) \\
\hline$\beta_{4}$ & 0.000471 & 0.00016 & $\alpha_{3}$ & 2.7708E-05* & $2.55 \mathrm{E}-05$ \\
\hline (Thursday) & $(1.4543)$ & $(0.4153)$ & & $(1.6852)$ & $(0.751)$ \\
\hline$\beta_{5}$ & $0.0009^{* * *}$ & 0.00045 & & & \\
\hline (Friday) & $(2.7431)$ & $(1.0679)$ & & & \\
\hline
\end{tabular}

Table 4. Estimates of models 5 and 6 for the period 2 January 1986-31 December 1997

Notes: ${ }^{*}, * *,{ }^{* * *}$ represent levels of significance of 10,5 and $1 \%$ respectively. 
The GARCH $(1,1)$ model was the most parsimonious from a variety of $A R C H, G A R C H$ specifications, that we experimented with, and that were satisfying the conditions of positive and stationary variance. More specifically, the GARCH $(1,1)$ models shown below were estimated with the quasi-maximum likelihood technique of Bollerslev and Wooldridge (1992) ${ }^{6}$, over the period 2 February 1986-31 December 1997

$$
\begin{aligned}
& R t=\beta_{1} D_{1 t}+\beta_{2} D_{2 t}+\beta_{3} D_{3 t}+\beta_{4} D_{4 t}+\beta_{5} D_{5 t}+\varepsilon t \\
& h_{t}=\alpha_{0}+\alpha_{1} \varepsilon_{t-1}^{2}+\alpha_{2} h_{t-1}^{2}+\alpha_{3} D_{1 t}
\end{aligned}
$$

$$
\begin{aligned}
& R S_{t}=\beta_{1} D_{1 t}+\beta_{2} D_{2 t}+\beta_{3} D_{3 t}+\beta_{4} D_{4 t}+\beta_{5} D_{5 t}+\varepsilon t \\
& h_{t}=\alpha_{0}+\alpha_{1} \varepsilon_{t-1}^{2}+\alpha_{2} h_{t-1}^{2}+\alpha_{3} D_{1 t}
\end{aligned}
$$

The Monday dummy was included in the conditional variance equation in order to formally test whether the inclusion of spread-adjusted returns (Equation 6) as opposed to standard returns (Equation 5) reduces the conditional volatility of stock returns due to day of the week effect.

As seen in Table 4, the coefficient of the Monday dummy $\left(\alpha_{3}\right)$ is significantly positive at the $10 \%$ level, when standard returns are employed (Equation 5), indicating that Mondays are associated with higher stock return conditional volatility. The mean Monday returns $\left(\beta_{1}\right)$ are negative and significant at the $10 \%$ level. These results are in accordance with the preliminary evidence in Tables 1-2. However, when transactions costs are accounted for, by employing spread-adjusted returns (Equation 6) the coefficient of the Monday dummy becomes insignificant in both the conditional mean and conditional variance equations. Thus, when transactions costs are considered the day of the week effect on Mondays appears to dwindle.

\section{SUMMARY AND CONCLUSION}

The first conclusion is that the day of the week effect exists in the UK stock market. This is in agreement with the previous literature such as Mills and Coutts (1995) and Arsad and Coutts (1997). The second conclusion is that once transactions costs have been accounted for, the day of the week effect seems to no longer be an enduring anomaly. This is because of the following reason. When one does not account for transactions costs one found that returns on Mondays were negative and significantly different from other days of the week implying that stocks were cheaper to buy on Mondays. This created the anomaly since investors seek to buy their stocks on Mondays, thus creating a day of the week effect. Once transactions costs were taken into consideration the returns on Mondays were not significantly different from the other days of the week.

This implied that stocks were no longer cheaper to buy on Mondays, which in turn suggested that the day of the week anomaly disappeared, giving evidence that markets were weak form efficient. The research was then extended to look at the day of the week effect from the point of view of volatility. Returns on Mondays were found had a higher standard deviation compared to the other days of the week. They were more volatile because investors traded more heavily on Mondays because of the day of the week anomaly. Then formal tests were carried out to examine whether the volatility was greater on Mondays by employing a GARCH $(1,1)$ model with a dummy reflecting trading on Mondays inserted into the conditional variance equation. The dummy was found to be significantly positive, which implied that there was greater trading volatility on Mondays, due to the existence of the day of the week anomaly. However, when transactions costs were considered the dummy became insignificant indicating that the volatility of trading on Mondays was not statistically different to the other days of the week. This is because once transactions costs were considered the day of the week effect diminished.

Overall, one concludes that once transactions costs are considered there is no day of the week effect on the UK stock market. This therefore leads us to the conclusion that the UK stock market appears to be weak form efficient. It is believed that the research could be extended by looking at other major stock markets to see if markets are efficient worldwide. This proposal is the author's own but was very difficult to move due to misavailability of data of the bid-ask spread for countries outside the UK.

\section{ACKNOWLEDGEMENTS}

This article has benefited by helpful comments and suggestions of M. Dixon and J. V. Healey, the authors are grateful for their input. The usual disclaimer applies.

\footnotetext{
${ }^{6}$ This method was employed due to the departure of the residuals from normality. The residuals were found to be non-normal with the use of the test proposed by Jarque-Bera (1987).
} 


\section{REFERENCES}

Aggarwal, R., Rao, P. and Hiraki, T. (1989) Skewness and kurtosis in Japanese equity returns: empirical evidence, The Journal of Financial Returns, 12, 253-60.

Arsad, Z. and Coutts, J. A. (1997) Security price anomalies in the London international Stock Exchange: a 60 year perspective, Applied Financial Economics, 7, 455-64.

Badrinath, S. G. and Chatterjee, S. (1991) A data-analytic look at skewness and elongation on common stock return distributions, Journal of Business and Economic Studies, 9, 223-33.

Bollerslev, T. (1986) Generalised autoregressive conditional heteroscedasticity, Journal of Econometrics, 31, 307-27.

Bollerslev, T. (1987) A conditionally heteroscedastic time-series model for speculative prices and rates of return, Review of Economics and Statistics, 69, 542-47.

Bollerslev, T. and Wooldridge, J. M. (1987) Quasi-maximum likelihood estimation and inference in dynamic models with time varying covariances, Econometric Review, 11, 143-72.

Bowers, J. and Dimson, E. (1988) Introduction, in Stock Market Anomalies (Ed.) E. Dimson, Cambridge University Press, Cambridge, pp. 3-15.

Connolly, R. A. (1989) An examination of the robustness of the weekend effect, Journal of Financial and Quantitative Analysis, 24, 133-69.

Connolly, R. A. (1991) A posterior odds analysis of the weekend effect, Journal of Econometrics, 49, 51-104.

Cross, F. (1973) The behaviour of stock prices on Mondays and Fridays, Financial Analysts Journal, Nov-Dec, 67-9.

Fama, E. (1965) The behaviour of stock market prices, Journal of Business, 38, 161-76.

Fishe, R. R. H., Gosnell, T. F. and Lasser, D. J. (1993) Good news, bad news, volume and the Monday effect, Journal of Business Finance and Accounting, 20, 881-92.

French, K. R. (1980) Stock returns and the weekend effect, Journal of Financial Economics, 8, 55-69.

Gibbons, M. R. and Hess, P. (1981) Day of the week effects, Journal of Business, 54, 579-96.

Jarque, C. M. and Bera, A. K. (1987) A test for normality of observations and regressions residuals, International Statistical Review, 55, 163-72.

Keim, D. B. and Stambaugh, R. F. (1984) A further investigation of the weekend effect in stock returns, Journal of Finance, 39, 819-35.

Lakonishok, J. and Levi, M. (1982) Weekends effects on stock returns: a note, Journal of Finance, 37, 883-89.

Lakonishok, J. and Smidt, S. (1988) Are seasonal anomalies real? A 90-year perspective, Review of Financial Studies, 1, 403-25.

Linn, S. C. and Lockwood, L. J. (1988) Short-term stock price patterns: NYSE, AMEX, OTC, Journal of Portfolio Management, 15, 30-4.

Mills, T. C. and Coutts, J. A. (1995) Calendar effects in the London Stock Exchange FTSE indices, The European Journal of Finance, 1, 79-93.

Philips-Patrick, F. J. and Schneeweis, T. (1988) The 'Weekend Effect' for stock indexes and stock index futures: dividend and interest rate effects, Journal of Future Markets, 8, 115-21.

Thaler, R. H. (1987a) The January effect, Journal of Economic Perspectives, 1, 197-201.

Thaler, R. H. (1987b) Seasonal movements in security prices II: weekend, holiday turn of the month, and intraday effects, Journal of Economic Perspectives, 1, 169-77. 